\title{
Musculoskeletal disorders and disability in persons aged 85 and over: a community survey
}

Dirkjan van Schaardenburg, Katrien J S Van den Brande, Gerard J Ligthart, Ferdinand C Breedveld, Johanna M W Hazes

\begin{abstract}
Objectives-To study the prevalences of musculoskeletal disorders and disability in the elderly, and the relationship between them.

Methods-A community sample of 73 females and 32 males aged 85 and over underwent a standardised examination at home. Musculoskeletal disorders were classified according to published clinical criteria. The relative effects on disability (a walking distance of $<500 \mathrm{~m}$ or dependency in activities of daily living (ADL)) of musculoskeletal disorders and comorbidity were analysed by logistic regression.

Results-Musculoskeletal pain was reported by $57 \%$ of those interviewed. A major restriction of joint movement range was frequent in the shoulder but uncommon in other joints. A shoulder disorder was found in $27 \%$ of subjects, rheumatoid arthritis in $1 \%$ and osteoarthritis (OA) of the hand, hip, and knee in five, seven, and $18 \%$ of subjects, respectively. Disability was frequent: a walking distance of $<500 \mathrm{~m}$ was found in $60 \%$ and ADL dependency in $40 \%$ of the group. Factors related to one or both of these disability measures included female gender, hip and knee $O A$, impaired vision, cognitive impairment and neurological disease.
\end{abstract}

Conclusion-Musculoskeletal pain and disorders, in addition to disability were frequent in this very elderly population. However, as a cause of disability, other disorders were at least as important as musculoskeletal disorders.

(Ann Rheum Dis 1994; 53: 807-811)

Department of

Rheumatology,

University Hospital,

Leiden, The

Netherlands

D van Schaardenburg

F C Breedveld

J M W Hazes

Section of

Gerontology, State

University, Leiden,

The Netherlands

KJ S Van den Brande

G J Ligthart

Correspondence to:

Dr van Schaardenburg,

University Hospital,

Department of

Rheumatology, PO Box

9600,2300 RC Leiden,

The Netherlands.

Accepted for publication

29 July 1994 community surveys gen document the presence of 'arthritis' by means of self report, but the definition of arthritis applied by a respondent to a questionnaire may differ from what a physician would classify as a musculoskeletal disorder. Also, sparse data suggest that self reported disability is more frequent than objective assessment of functional limitations would predict, ${ }^{11}$ especially in very elderly individuals with cognitive impairment. ${ }^{12}$ The true prevalence of musculoskeletal disorders in the elderly and the extent to which they cause physical disability are uncertain, but $25-50 \%$ of those aged 85 and more have been reported to have limitations of basic physical abilities, depending on the definitions used. ${ }^{3-5}$ The rapid increase in the absolute number of these very elderly subjects in the industrialised countries has major implications in terms of provision of care.

We investigated the prevalence of musculoskeletal pain and disorders and their association with physical disability in a crosssectional health survey of people aged 85 and over in the general Dutch population. The modifying effect of comorbidity was taken into account.

\section{Methods}

\section{STUDY SUBJECTS}

The study formed part of a community survey in persons aged 85 years and over by the Section of Gerontology of Leiden University. The town of Leiden is a community of approximately 105000 inhabitants; the elderly inhabitants are an ethnically homogeneous group. The names and addresses of all inhabitants aged 85 years or more on 1 August 1990 were obtained from the civic register (total number 1468; 1103 females, 365 males, median age 88 years, range $85-105)$. From the alphabetically ordered list a random sample of 368 was drawn by selecting every fourth person. With approval of the Committee for Medical Ethics of the Leiden University Hospital, these 368 persons were invited in random order, by a letter and a telephone call, to participate in a health survey. Sixty six had died before the first contact could be made and 63 did not wish to participate. The remaining 239 were visited at home by a physician (KVDB). The first visit comprised a medical history, questionnaire regarding activities of daily life (ADL) and tests of vision and cognition to assess the presence of disability and comorbidity (as defined below): When necessary, the history and the questionnaire were completed with the help of the main caregiver. Every second one of the 239 elderly was asked to permit another visit, by a rheumatologist (DVS) (the others were recruited for a study on lung disease). Fourteen 
$(12 \%)$ did not wish to be visited again and one died before the second visit. The remaining 73 females and 32 males were included in the present study. Their median age was 89 years (range $85-100)$. Forty-five of them (43\%) lived in a home for the elderly and five (5\%) in a nursing home. In the Netherlands, inhabitants of a home for the elderly receive assistance if necessary, but otherwise live independently. Inhabitants of nursing homes receive full nursing care. Fifty-five of the group $(52 \%)$ lived independently with or without their family. Visits were made between 1 January 1991 and 15 May 1992. The median interval between the two visits was seven days.

MUSCULOSKELETAL EXAMINATION

The visit by the rheumatologist comprised a history and physical examination of the musculoskeletal system. Participants were asked if, during most days of the preceding month, they had experienced pain in seven areas of the body listed (table 1). Answers were scored positive or negative without reference to intensity. The presence and duration of morning stiffness were recorded. Spinal mobility was measured as the change in distance $\mathrm{C} 7-\mathrm{S} 1$ between standing upright and at maximal active flexion of the spine. The passive range of motion of the right shoulder, hip and knee was measured with a two arm goniometer; only forward flexion of the shoulder was measured actively. Reference values were obtained from a publication of the American Academy of Orthopaedic Surgeons. ${ }^{13}$ Shoulder flexion was measured with the $0^{\circ}$ plane parallel to the upper thoracic spine, as values relative to a vertical plane from the shoulder downwards would lead to erroneously low values in subjects with kyphosis. The intra- and interobserver reliability of joint range of movement measurements has been shown to be high. ${ }^{14}$

MUSCULOSKELETAL DISORDERS

In the circumstances of our study it was not possible to obtain radiographs, so participants were classified according to published clinical criteria, for rheumatoid arthritis (American Rheumatism Association (ARA) criteria), ${ }^{15}$ past polyarthritis with joint deformity ('New York' criteria), ${ }^{16}$ past polyarthritis without joint deformity ('benign polyarthritis'), ${ }^{17}$ and OA of the hand, ${ }^{18}$ hip, ${ }^{19}$ and knee. ${ }^{20}$ Persons with current synovitis who did not fulfil the criteria for rheumatoid arthritis were classified as having oligoarthritis. The prevalence of $\mathrm{OA}$ of the hand, hip, or knee was determined using a classification based on clinical criteria alone. ${ }^{18-20}$ Shoulder disorders were classified according to Chard et al. ${ }^{21} \mathrm{~A}$ frozen shoulder was defined as a restriction of at least $50 \%$ of the normal range of motion of passive forward flexion, glenohumeral abduction, exorotation or endorotation in the absence of arthritis or bony restriction. Rotator cuff tendinitis was defined as the presence of a painful arc of motion on abduction or pain during resisted abduction, exorotation, or endorotation. OA of the glenohumeral joint was diagnosed if there was bony crepitus in this joint in the absence of synovitis.

Other conditions elicited by history and physical examination were classified according to diagnostic recommendations in standard textbooks of rheumatology.

\section{DISABILITY}

Two disability measures were used, representing function of the lower extremity and overall independent function. Walking disability was defined as a walking distance of $<500 \mathrm{~m}$, derived from asking how far a person walked outside at least twice a month. Overall independent function was measured with the Katz ADL index, excluding reference to incontinence. ${ }^{22} \mathrm{ADL}$ dependency was defined as receiving human assistance in any of the activities.

\section{COMORBIDITY}

Comorbidity factors were: impaired vision, impaired cognition, neurological disease, impaired oxygenation, and obesity. Impaired vision was defined as a vision of less than 0.5 in the Jaeger eye test, ${ }^{23}$ cognitive impairment as a score of $0-23^{24}$ on the mini mental state examination (MMSE) scale of $0-30 .{ }^{25}$ Neurological disease was defined as the presence of one or more of: history of cerebrovascular accident or trauma to the central nervous system with persistent paresis, history of Parkinsonism, history of epilepsy. Impaired oxygenation was scored in the presence of heart disease (New York Heart Association class $>1$ ), pulmonary disease (more than slight dyspnoea on exertion), or intermittent claudication. Obesity was defined by a body mass index $\geqslant 27 \mathrm{~kg} / \mathrm{m}^{2}$, with body weight measured with a digital scale and height estimated on the basis of arm length measurements using a nomogram. ${ }^{26}$

\section{STATISTICAL ANALYSIS}

Differences between groups were tested with the $\chi^{2}$ test and the Mann-Whitney $U$ test, as appropriate (tables $1-3$ ). In a bivariate analysis ( $\chi^{2}$ test) (table 4$)$, the following factors were tested for their relation to the measures of disability: age $(90+v 85-89)$, gender, presence of OA of the hip or the knee, presence of a shoulder disorder, comorbidity items, and musculoskeletal pain at the appropriate site. A multivariate logistic regression analysis (SPSS program) was performed to determine the relative contribution to disability of the various measures of morbidity. Results were expressed as odds ratios with $95 \%$ confidence intervals (table 5); pain items were then added to the model one at a time to examine whether they provided an additional explanation for the presence of disability.

Finally, for both disability measures the number of persons was counted without any of the morbidity or pain items. To this end, 
cognitive impairment was divided into severe (MMSE score $\leqslant 17$ ) and mild (MMSE score $18-23) .^{24}$

\section{Results}

HISTORY OF BACK OR JOINT PAIN

Back pain or joint pain, or both, was present in $57 \%$ of the group (females $62 \%$, males $47 \%$ ) (table 1). Pain was most frequently in the back, shoulder, and knee. For several joints, women reported pain more often than men, but the difference was statistically significant only for the wrist and hand. Morning stiffness lasting one hour or more was recorded in $2 \%$ of the group.

Table 1 Prevalence of current back or joint pain

\begin{tabular}{llll}
\hline Pain localisation & $\begin{array}{l}\text { Females } \\
(n=73) \\
(\%)\end{array}$ & $\begin{array}{l}\text { Males } \\
(n=32) \\
(\%)\end{array}$ & $\begin{array}{l}\text { Total } \\
(n=105) \\
(\%)\end{array}$ \\
\hline Thoracolumbar spine & 28 & 28 & 28 \\
Shoulder & 29 & 19 & 26 \\
Elbow & 4 & 6 & 5 \\
Hand and wrist & $18^{\star}$ & 3 & 13 \\
Hip & 12 & 12 & 12 \\
Knee & 26 & 19 & 24 \\
Foot and ankle & 10 & 0 & 7 \\
\hline
\end{tabular}

${ }^{\star} \mathrm{p}<0.05$ compared with males.

Table 2 Spinal mobility and range of motion of the right shoulder, hip, and knee

\begin{tabular}{|c|c|c|c|c|c|}
\hline \multicolumn{2}{|l|}{ Site } & $\begin{array}{l}\text { Normal } \\
\text { value }\end{array}$ & $\begin{array}{l}\text { Females } \\
(n=73)\end{array}$ & $\begin{array}{l}\text { Males } \\
(n=32)\end{array}$ & $\begin{array}{l}\text { Total } \\
(n=105)\end{array}$ \\
\hline \multicolumn{2}{|c|}{ Spinal mobility $(\mathrm{cm})$} & 10 & $7(2)$ & $8(2)$ & $7(2)$ \\
\hline $\begin{array}{l}\text { ROM (de } \\
\text { Should }\end{array}$ & $\begin{array}{l}\text { forward flexion, active } \\
\text { forward flexion, passive } \\
\text { exorotation } \\
\text { endorotation } \\
\text { glenohumeral abduction }\end{array}$ & $\begin{array}{r}180 \\
180 \\
90 \\
90 \\
90\end{array}$ & $\begin{array}{r}131(35) \\
147(25) \\
79(16) \\
79(17) \\
83(11)\end{array}$ & $\begin{array}{r}135(33) \\
150(19) \\
80(13) \\
73(19) \\
84(11)\end{array}$ & $\begin{array}{r}133(34) \\
148(23) \\
79(15) \\
77(17) \\
83(11)\end{array}$ \\
\hline Hip: & $\begin{array}{l}\text { flexion } \\
\text { flexion contracture } \\
\text { abduction } \\
\text { endorotation } \\
\text { exorotation }\end{array}$ & $\begin{array}{r}120 \\
0 \\
- \\
- \\
-\end{array}$ & $\begin{array}{l}115(8) \\
6(16) \\
34(12)^{\star} \\
31(14)^{\star} \\
46(15)\end{array}$ & $\begin{array}{c}117(8) \\
1(6) \\
38(8) \\
24(11) \\
44(13)\end{array}$ & $\begin{array}{r}116(8) \\
4(14) \\
35(11) \\
29(13) \\
45(14)\end{array}$ \\
\hline Knee: & $\begin{array}{l}\text { flexion } \\
\text { flexion contracture }\end{array}$ & $\begin{array}{r}135 \\
0\end{array}$ & $\begin{array}{c}126(11)^{\star} \\
4(15)\end{array}$ & $\begin{array}{c}130(15) \\
1(4)\end{array}$ & $\begin{array}{r}127(13) \\
3(12)\end{array}$ \\
\hline
\end{tabular}

fObtained in healthy young adults $;^{13}$ other results are mean(SD). ROM $=$ Range of motion. ${ }^{\star} p<0.05$ compared with males.

Table 3 Prevalence of musculoskeletal disorders

\begin{tabular}{|c|c|c|c|c|c|c|}
\hline \multirow[t]{2}{*}{ Disorder } & \multicolumn{2}{|c|}{$\begin{array}{l}\text { Females } \\
(n=73)\end{array}$} & \multicolumn{2}{|c|}{$\begin{array}{l}\text { Males } \\
(n=73)\end{array}$} & \multicolumn{2}{|c|}{$\begin{array}{l}\text { Total } \\
(n=105)\end{array}$} \\
\hline & $n$ & $(\%)$ & $n$ & $(\%)$ & $n$ & (\%) \\
\hline $\begin{array}{l}\text { Polyarthritis } \\
\text { Rheumatoid arthritis } \\
\text { Past polyarthritis with joint deformity } \\
\text { Past polyarthritis without joint deformity }\end{array}$ & $\begin{array}{l}1 \\
2 \\
2\end{array}$ & $\begin{array}{l}\text { (1) } \\
\text { (3) } \\
\text { (3) }\end{array}$ & $\begin{array}{l}\overline{1} \\
-\end{array}$ & (3) & $\begin{array}{l}1 \\
3 \\
2\end{array}$ & $\begin{array}{l}\text { (1) } \\
\text { (3) } \\
\text { (2) }\end{array}$ \\
\hline Oligoarthritis & 7 & (10) & 5 & (16) & 12 & (11) \\
\hline $\begin{array}{l}\text { Osteoarthritis } \\
\text { Hand }\end{array}$ & 5 & (7) & - & & 5 & (5) \\
\hline $\begin{array}{l}\text { Hip } \\
\text { Hip prosthesis } \dagger \text { ( } 1 \text { or } 2 \text { sides) }\end{array}$ & $\begin{array}{r}4 \\
10 \\
\end{array}$ & $\begin{array}{r}(6) \\
(14) \\
\end{array}$ & $\begin{array}{l}3 \\
1 \\
\end{array}$ & $\begin{array}{l}(9) \\
(3) \\
\end{array}$ & $\begin{array}{r}7 \\
11 \\
\end{array}$ & $\begin{array}{r}(7) \\
(11) \\
\end{array}$ \\
\hline Total: & 14 & (19) & 4 & (13) & 18 & (17) \\
\hline $\begin{array}{l}\text { Knee } \\
\text { Knee prosthesis† ( } 2 \text { sides) }\end{array}$ & $\begin{array}{r}14 \\
1 \\
\end{array}$ & $\begin{array}{r}(19) \\
(1) \\
\end{array}$ & $\begin{array}{l}5 \\
- \\
\end{array}$ & (16) & $\begin{array}{r}19 \\
1 \\
\end{array}$ & $\begin{array}{r}(18) \\
(1) \\
\end{array}$ \\
\hline Total: & 15 & (21) & 5 & (16) & 20 & (19) \\
\hline $\begin{array}{l}\text { Shoulder disorders } \\
\text { Frozen shoulder } \\
\text { Osteoarthritis } \\
\text { Synovitis } \\
\text { Rotator cuff tendinitis } \\
\text { Bicipital tendinitis } \\
\text { Acromioclavicular luxation } \\
\text { Any shoulder disorder }\end{array}$ & $\begin{array}{r}12 \\
3 \\
3 \\
3 \\
1 \\
- \\
20\end{array}$ & $\begin{array}{r}(16) \\
(4) \\
(4) \\
(4) \\
(1) \\
(27)\end{array}$ & $\begin{array}{l}6 \\
1 \\
- \\
- \\
- \\
1 \\
8\end{array}$ & $\begin{array}{r}(19) \\
(3)\end{array}$ & $\begin{array}{r}18 \\
4 \\
3 \\
3 \\
1 \\
1 \\
28\end{array}$ & $\begin{array}{r}(17) \\
(4) \\
(3) \\
(3) \\
(1) \\
(1) \\
(27)\end{array}$ \\
\hline
\end{tabular}

Osteoarthritis and shoulder disorders were scored independently of the presence of poly- or oligoarthritis. Differences between sexes not significant. + The indication for surgery was OA in all cases.
MUSCULOSKELETAL EXAMINATION

Table 2 shows spinal mobility and the mean range of movement of large joints. Any restriction of joint motion was mostly slight, except for the shoulder, in which active forward flexion of $120^{\circ}$ or less was present in $31 \%$ of subjects. Hip flexion of less than $90^{\circ}$ was not found; flexion contracture of the hip of $15^{\circ}$ or more was present in $11 \%$ of the group. One percent of the group had knee flexion of less than $90^{\circ}$ and $9 \%$ had a flexion contracture of the knee of $15^{\circ}$ or more.

PREVALENCE OF MUSCULOSKELETAL DISORDERS Six persons had suffered or still suffered from polyarthritis. The age at onset varied from 41 years to 87 years (median 75 ). In two subjects the arthritis had subsided without joint deformity (benign polyarthritis), and three others no longer had active arthritis but had residual joint deformity (New York criteria); active rheumatoid arthritis (ARA criteria) was present in only one. Oligoarthritis was found in 12 persons (table 3$)$, at the shoulder $(n=2)$, wrist $(n=1)$, metacarpophalangeal joints $(n=3)$, proximal interphalangeal joints $(n=1)$, and knee $(n=7)$. One person had onesided arthritis of the metacarpophalangeal joints in conjunction with the clinical picture of polymyalgia rheumatica. Five of seven subjects with monoarthritis of the knee were also classified as having OA of the knee.

Prevalence of OA was low; more females than males had OA, but the difference was not statistically significant (table 3).

A shoulder disorder was present in $27 \%$ of the group (table 3). Two of these had both synovitis with bicipital tendinitis, and frozen shoulder with rotator cuff tendinitis. A frozen shoulder, the most frequent shoulder disorder (18 subjects), was bilateral in four; in another four the frozen shoulder was associated with stroke (three) and fracture of the humerus (one).

Sixty eight percent of those with knee pain had a diagnosis of knee OA; approximately $50 \%$ of those with pain at the shoulder, hand, or hip, had a joint disorder.

In no subject was there clinical evidence of other major musculoskeletal disorders such as gout or spondylarthropathy.

\section{DISABILITY}

There was a high level of disability in this population: $60 \%$ walked less than $500 \mathrm{~m}$ outdoors alone and $40 \%$ received human assistance in performing daily activities. Bivariate analysis revealed significant association with one or both of the disability measures, for female gender, OA of the knee, a shoulder disorder, impaired vision, impaired cognition and knee pain per se (table 4 ).

After multivariate analysis (table 5), most of the associations did not change substantially. However, adjusting for the presence of the other factors resulted in a stronger association of neurological disease with walking $<500 \mathrm{~m}$, impaired vision was now no longer significantly 
Table 4 Bivariate analysis of variables possibly related to two measures of disability

\begin{tabular}{|c|c|c|c|c|c|c|c|}
\hline & \multirow{2}{*}{$\begin{array}{l}\text { Overall } \\
\text { frequency } \\
(\%)\end{array}$} & \multicolumn{3}{|l|}{ Walks } & \multicolumn{3}{|l|}{$A D L$} \\
\hline & & $\begin{array}{l}<500 m \\
(n=63) \\
(\%)\end{array}$ & $\begin{array}{l}\geqslant 500 m \\
(n=42) \\
(\%)\end{array}$ & $\begin{array}{l}\text { Odds } \\
\text { ratio }\end{array}$ & $\begin{array}{l}\text { Dependent } \\
(n=42) \\
(\%)\end{array}$ & $\begin{array}{l}\text { Independent } \\
(n=63) \\
(\%)\end{array}$ & $\begin{array}{l}\text { Odds } \\
\text { ratio }\end{array}$ \\
\hline Age 90 and over & 44 & 51 & 33 & $2 \cdot 1$ & 52 & 38 & 1.8 \\
\hline Female gender & 70 & 78 & 57 & $4 \cdot 7^{\star}$ & 81 & 62 & $2 \cdot 6^{\star}$ \\
\hline \multicolumn{8}{|l|}{ Morbidity measures } \\
\hline OA hip & 7 & 10 & 2 & $4 \cdot 3$ & 7 & 6 & $1 \cdot 1$ \\
\hline OA knee & 18 & 29 & 2 & $16 \cdot 4^{\star}$ & 21 & 16 & $1 \cdot 4$ \\
\hline Shoulder disorder & 27 & - & - & - & 38 & 19 & $2 \cdot 6^{\star}$ \\
\hline Impaired vision & 29 & 37 & 17 & $2 \cdot 9^{\star}$ & 49 & 16 & $5 \cdot 0^{\star}$ \\
\hline Impaired cognition & 46 & 60 & 24 & $4 \cdot 9^{\star}$ & 67 & 32 & $4 \cdot 3^{\star}$ \\
\hline Neurological disease & 15 & 21 & 7 & $3 \cdot 4$ & 21 & 11 & $2 \cdot 2$ \\
\hline Impaired oxygenation & 19 & 22 & 14 & 1.7 & 12 & 24 & $0 \cdot 4$ \\
\hline Obesity & 25 & 26 & 24 & $1 \cdot 1$ & 20 & 29 & 0.6 \\
\hline \multicolumn{8}{|l|}{ Pain } \\
\hline Pain back & 28 & 33 & 21 & $1 \cdot 8$ & 21 & 33 & 0.5 \\
\hline Pain shoulder & 26 & - & - & - & 17 & 31 & $0 \cdot 4$ \\
\hline Pain hip & 13 & 14 & 10 & 1.5 & 14 & 11 & $1 \cdot 3$ \\
\hline Pain knee & 24 & 32 & 12 & $3 \cdot 3^{\star}$ & 26 & 23 & $1 \cdot 2$ \\
\hline
\end{tabular}

- Not tested. $\nmid$ Differences between sexes were not significant. ${ }^{\star} \mathrm{p}<0.05$.

Table 5 Results of logistic regression analysis of two measures of disability, expressed as odds ratios with confidence intervals

\begin{tabular}{|c|c|c|}
\hline & $\begin{array}{l}\text { Walks }<500 \mathrm{~nm} \\
\text { OR }(95 \% \mathrm{CI})\end{array}$ & $\begin{array}{l}\text { ADL dependent } \\
\text { OR }(95 \% C I)\end{array}$ \\
\hline Age 90 or over & $2 \cdot 1(0.7$ to 6$)$ & $1.8(0.6$ to 5$)$ \\
\hline Female gender & $5 \cdot 1(1.5$ to 17$)$ & $4 \cdot 4(1.3$ to 15$)$ \\
\hline OA hip & $15.7(0.9$ to 270$)$ & $0.8(0.2$ to 4$)$ \\
\hline OA knee & $27.8(2.6$ to 302$)$ & $1.6(0.5$ to 6$)$ \\
\hline Shoulder disorder & - & $2 \cdot 1(0 \cdot 7$ to 7$)$ \\
\hline Impaired vision & $1.8(0.5$ to 6$)$ & $5 \cdot 1(1.5$ to 18$)$ \\
\hline Impaired cognitio & $5 \cdot 1(4 \cdot 7$ to 15$)$ & $2.8(1.02$ to 8$)$ \\
\hline Neurological disease & $8.9(1.4$ to 56$)$ & $1.9(0.4$ to 10$)$ \\
\hline Impaired oxygenation & $1.6(0.4$ to 6$)$ & $0.4(0.1$ to 1.7$)$ \\
\hline Obesity & $0.6(0.2$ to 2$)$ & $0.3(0.1$ to 1.2$)$ \\
\hline
\end{tabular}

associated with walking $<500 \mathrm{~m}$, and a shoulder disorder was no longer associated with ADL dependency. Inclusion of pain items had little effect on results for other variables in the model, and none of the pain items was significantly related to disability in the multivariate analysis (data not shown).

Twenty per cent of walking disability and $19 \%$ of ADL dependency could be explained by the morbidity measures in the model. None of the morbidity or pain items was present in $8 \%$ of subjects with a walking disability and $12 \%$ of those with $\mathrm{ADL}$ dependency. If cognitive impairment was included only when severe, these values became 19 and $21 \%$, respectively.

\section{Discussion}

In this community survey of people aged 85 years and over, slightly more than half reported back or joint pain. Moderate restrictions of joint movement range compared with the norm in young adults were quite common. The most prevalent musculoskeletal disorders were knee OA and frozen shoulder. Physical disability was also frequent. Strong independent associations with one or both of the disability measures (walking $<500 \mathrm{~m}$ and ADL dependency) were found for female gender, hip and knee OA, impaired vision, cognitive impairment, and neurological disease.

The $57 \%$ prevalence of back or joint pain in the present study is similar to that of $54 \%$ found in the United Kingdom ${ }^{4}$ and slightly greater than the $39 \%$ found in Sweden ${ }^{27}$ in the same age group. Restricted movement ranges of the shoulder, hip, and knee were more frequent and more severe in the present study population (average age 90) compared with a Swedish cohort of 79 year olds, ${ }^{28}$ reflecting considerable loss of range after the age of 79 . Two other surveys from the United Kingdom reported loss of shoulder flexibility in subjects older than 74 compared with that in a group aged $65-74 .{ }^{29}{ }^{30}$ However, in a study in which subjects were selected for good health, ${ }^{31}$ there was no loss of range of movement in a group aged $75-84$ as compared with that in a group aged 60-69. This suggests that a decrease in joint movement range is not a consequence of ageing itself but rather of age-related increase in diseases.

The prevalence of polyarthritis was low, as has been reported before in this age group. ${ }^{32} 33$ Rheumatoid arthritis was rare in this group; it is unlikely that this observation was distorted by our lack of access to rheumatoid factor tests and radiographs. The prevalence of OA also was low in this population, particularly when compared with that predicted by radiographic studies. ${ }^{34}$ This arises from the American College of Rheumatology (ACR) requirement that pain be a symptom if $\mathrm{OA}$ is to be diagnosed by clinical criteria alone. These criteria for OA were developed in a clinical setting, in which all patients studied had pain. However, it has been found before that only $50 \%$ of subjects with radiographic evidence of $\mathrm{OA}$ are symptomatic, ${ }^{35}$ and it appears that, in community surveys, the requirement to include pain in criteria for diagnosis of OA makes the approach insufficiently sensitive to detect OA. ${ }^{36}$

The frequency of shoulder disorders in this age group has only recently become recognised. ${ }^{21} 30313738$ In the current survey, pain and a relatively more restricted movement were more prevalent in the shoulder than in the hip or knee. The most frequent shoulder disorder was frozen shoulder, but the majority of those with this condition were asymptomatic and the cause of the restriction was mostly uncertain. Previously, rotator cuff tendinitis was recognised as the most usual shoulder disorder, but in those reports younger populations were studied. ${ }^{21} 30$ 
Disability in the elderly may be related to various diseases. Previous studies of adults aged 55 and over showed that the degree of disability is augmented considerably when musculoskeletal disorders occur in association with other chronic conditions. ${ }^{39}$ In the present study in a group aged 85 and over, cognitive impairment appears to be the most important exacerbating factor, followed by impaired vision, neurological disease and OA of the hip or the knee. Other factors that we did not measure must also play a part in causing the disability we observed, as the morbidity measures studied were able to explain only around $20 \%$ of the variation in disability. The multifactorial nature of disability which we found suggests that the role of musculoskeletal disorders in causing disability at very advanced ages is less important than is generally inferred from self reported data in younger populations. $^{6-9}$

Disability in the elderly is a consequence of disease or disuse, or both. Whatever the cause, it may be expected that some, at least, of the disabled persons are capable of functional improvement-in particular those without recognisable morbidity. In recent years, successful training programmes have led to improvement of muscle function and reduced $\mathrm{ADL}$ dependency in elderly patients with knee OA, ${ }^{40}$ and in those resident in homes for the elderly. ${ }^{41}$

In summary, the most frequent musculoskeletal findings in this survey were a severe restriction of the range of movement of the shoulder, and knee OA. Disability was determined by several disorders within and without the musculoskeletal system. In several of the disabled persons there was no apparent clinical cause, suggesting the possibility that a considerable increase in physical ability could be achieved in this elderly group.

We are grateful to Prof. J P Vandenbroucke, epidemiologist, for his review of the manuscript. The study was supported in part by a grant from the Dutch Ministry of Welfare, Health and Culture (grant no. 90-08) and was performed in collaboration with the Leiden Osteoarthritis Working Party.

1 Nagi S Z. An epidemiology of disability among adults in the United States. Milbank $O$ 1976; 54: 439-67.

2 Jette A M, Branch L G. The Framingham disability study: II. Physical disability among the aging. Am $\mathcal{f}$ Public Health 1981; 71: 1211-6.

3 Cornoni-Huntley J C, Foley D J, White L R, et al. Epidemiology of disability in the "oldest old": methodologic issues and preliminary findings. Milbank $Q$ 1985; 63: 350-76.

4 Badley E M, Tennant A. Changing profile of joint disorders with age: findings from a postal survey of the population of Calderdale, West Yorkshire, United Kingdom. Ann Rheum Dis 1992; 51: 366-71.

5 Reynolds D L, Chambers L W, Badley E M, et al. Physical disability among Canadians reporting musculoskeletal diseases. $f$ Rheumatol 1992; 19: 1020-30.

6 Physical disability in 1986 and beyond. A report of the Royal College of Physicians. F R Coll Physicians Lond 1986; 20 : 161-94.

7 Yelin E. Arthritis, the cumulative impact of a common chronic condition. Arthritis Rheum 1992; 35: 489-97.

8 Hubert H B, Bloch D A, Fries J F. Risk factors for physical disability in an aging cohort: the NHANES I epidemiologic followup study. $\mathcal{f}$ Rheumatol 1993; 20: 480-8.

9 Valkenburg H A. Epidemiologic considerations of the geriatric population. Gerontology 1988; 34(Suppl. 1): 2-10.

10 Lagaay A M, van Asperen I A, Hijmans W. The prevalence of morbidity in the oldest old, aged 85 and over: a population based survey in Leiden, The Netherlands. Arch Gerontol Geriatr 1992; 15: 115-31

11 Cunningham L S, Kelsey J L. Epidemiology of musculoskeletal impairments and associated disability. Am $\mathcal{}$ Public Health 1984; $74: 574$.
12 Kelly-Hayes M, Jette A M, Wolf P A, D'Agostino R B, Odell $P$ M. Functional limitations and disability among elders in the Framingham study. Am $\mathcal{F}$ Public Health 1992; 82: $841-5$.

13 American Academy of Orthopaedic Surgeons. Foint motion. Method of measuring and recording. Reprinted by the British Orthopaedic Association. Edinburgh: Churchill Orthopaedic Assod

14 Vliet Vlieland T P M, van den Ende C H M, Breedveld F $\mathrm{C}$, Hazes J M W. Evaluation of joint mobility in rheumatoid arthritis trials: The value of the EPM-range of motion scale. $\mathcal{F}$ Rheumatol 1993; 20: 2010-4.

15 Arnett F C, Edworthy S M, Bloch D A, et al. The American Rheumatism Association 1987 revised criteria for the classification of rheumatoid arthritis. Arthritis Rheum 1988; 31: 315-24.

16 Bennett B H, Burch T A. New York symposium on population studies in the rheumatic diseases: new diagnostic criteria. Bull Rheum Dis 1967; 17: 453-8.

17 Lawrence J S. Rheumatism in populations. London: Heineman Medical Books Ltd, 1977: 272-4.

18 Altman R, Alarcon G, Appelrouth D, et al. The American College of Rheumatology criteria for the classification and reporting of osteoarthritis of the hand. Arthritis Rheum 1990; 33: 1601-10.

19 Altman R, Alarcon G, Appelrouth D, et al. The American College of Rheumatology criteria for the classification and reporting of osteoarthritis of the hip. Arthritis Rheum 1991; 34: 505-14.

20 Altman R, Asch E, Bloch D, et al. Development of criteria for the classification and reporting of osteoarthritis. for the classification and reporting of osteoarthritis. 1986; 29: 1039-49.

21 Chard M D, Hazleman R, Hazleman B L, King R H, Reiss B B. Shoulder disorders in the elderly: a community survey. Arthritis Rheum 1991; 34: 766-9.

$22 \mathrm{Katz}$ S, Downs T D, Cash H R, Grotz R C. Progress in development of the index of ADL. Gerontologist 1970; 10: 20-30.

23 Lachs M S, Feinstein A R, Cooney L M, et al. A simple procedure for general screening for functional disability in procedure for general screening for functional disability

24 Tombaugh T N, McIntyre N J. The mini-mental state examination: a comprehensive review. $\mathcal{f}$ Am Geriatr Soc 1992; 40: 922-35.

25 Folstein M F, Folstein S E, McHugh P R. "Mini-Mental State", a practical method for grading the cognitive state of patients for the clinician. $\mathcal{F}$ Psychiatr Res 1975; 12: 189-98.

26 Haboubi N Y, Hudson P R, Pathy M S. Measurement of height in the elderly. $\mathcal{f} A m$ Geriatr Soc 1990; 38: 1008-10.

27 Bagge E, Bjelle A, Eden S, Svanborg A. Osteoarthritis in the elderly: clinical and radiological findings in 79 and 85 year elderly: clinical and radiological findings

28 Bergström G, Bjelle A, Sorensen L B, Sundh V, Svanborg A. Prevalence of symptoms and signs of joint impairment at age 79. Scand f Rehab Med 1985; 17: 173-82.

29 Bassey E J, Morgan K, Dallosso H M, Ebrahim S B J. Flexibility of the shoulder joint measured as range of abduction in a large representative sample of men and women over 65 years of age. Eur 7 Appl Physiol 1989; 58: 353-60.

30 Chakravarty K, Webley M. Shoulder joint movement and its relation to disability in the elderly. 7 Rheumatol 1993 ; 20: $1359-61$.

31 Walker J M, Sue D, Miles-Elkousy N, Ford G, Trevelyan $\mathrm{H}$. Active mobility of the extremities in older subjects. Phys Ther 1984; 64: 919-23.

32 Schaardenburg D van, Lagaay A M, Breedveld F C, Hijmans W, Vandenbroucke J P. Rheumatoid arthritis in a population of persons aged 85 years and over. $\mathrm{Br} \mathcal{F}$ Rheumatol 1993; 32: 104 -9.

33 Ward R H, Hasstedt S J, Clegg D O. Population prevalence of rheumatoid arthritis is lower than formerly supposed. Arthritis Rheum 1992; 35: S126.

34 Saase van J L C M, van Romunde L K J, Cats A, Vandenbroucke J P, Valkenburg H A. Epidemiology of osteoarthritis: Zoetermeer survey, comparison of radiological osteo-arthritis in a Dutch population with 10 other populations. Ann Rheum Dis 1989; 48: 455-60.

35 Lawrence R C, Hochberg M C, Kelsey J L, et al. Estimates of the prevalence of selected arthritic and musculoskeletal diseases in the United States. $\mathcal{F}$ Rheumatol 1989; 16: 427-41.

36 Hart D J, Leedham-Green M, Spector T D. The prevalence of knee osteoarthritis in the general population using
different clinical criteria: the Chingford study. $B r \quad \mathcal{F}$ different clinical criteria

37 Chard M D, Hazleman B L. Shoulder disorders in the elderly (a hospital study). Ann Rheum Dis 1987; 46: 684-7.

38 Chakravarty K K, Webley M. Disorders of the shoulder: an often unrecognised cause of disability in elderly people. $B M 7$ 1990; 300: 848-9.

39 Verbrugge L M, Lepkowski J M, Konkol L L. Levels of disability among U.S. adults with arthritis. $f$ Gerontol 1991; 46: S71-83.

40 Fisher N M, Pendergast D R, Gresham G E, Calkins E. Muscle rehabilitation: its effect on muscular and functional performance of patients with knee osteofunctional performance of patients with knee
arthritis. Arch Phys Med Rehabil 1991; 72: 367-74.

41 McMurdo M E T, Rennie L. A controlled trial of exercise by residents of old people's homes. Age Ageing 1993; 22: $11-5$. 